Article

\title{
Improving S-Band Polarimetric Radar Monsoon Rainfall Estimation with Two-Dimensional Video Disdrometer Observations in South China
}

\author{
Zeyong Guo ${ }^{1}$, Sheng $\mathrm{Hu}^{2}$, Xiantong Liu ${ }^{2, *}$, Xingdeng Chen ${ }^{1}$, Honghao Zhang ${ }^{1}$, Tao Qi ${ }^{3}$ and Guangyu Zeng ${ }^{1}$ \\ 1 Yangjiang Meteorological Bureau, China Meteorological Administration, Yangiiang 529500, China; \\ guozeyong1982@163.com (Z.G.); cgxgdg1985@163.com (X.C.); zhanghonghao0508@163.com (H.Z.); \\ zengguangyu@163.com (G.Z.) \\ 2 Institute of Tropical and Marine Meteorology, China Meteorological Administration, \\ Guangzhou 510640, China; sheng_hu@gd121.cn \\ 3 China Meteorological Administration, Beijing 100081, China; footprint0601@163.com \\ * Correspondence: xtliu@gd121.cn
}

check for

updates

Citation: Guo, Z.; Hu, S.; Liu, X.; Chen, X.; Zhang, H.; Qi, T.; Zeng, G. Improving S-Band Polarimetric Radar Monsoon Rainfall Estimation with Two-Dimensional Video Disdrometer Observations in South China. Atmosphere 2021, 12, 831. https:// doi.org/10.3390/atmos12070831

Academic Editors: Wen Zhou and Carlos M. Carrillo

Received: 27 May 2021

Accepted: 25 June 2021

Published: 28 June 2021

Publisher's Note: MDPI stays neutral with regard to jurisdictional claims in published maps and institutional affiliations.

Copyright: (c) 2021 by the authors. Licensee MDPI, Basel, Switzerland. This article is an open access article distributed under the terms and conditions of the Creative Commons Attribution (CC BY) license (https:/ / creativecommons.org/licenses/by/ $4.0 /)$.

\begin{abstract}
The capability to estimate monsoon rainfall is investigated by using S-band polarimetric radar (S-POL) and two-dimensional Video Disdrometer (2DVD) during 2017-2018 in South China. Based on 2 years of 2DVD raindrop size distribution (DSD) observations of monsoon precipitation systems, four different quantitative precipitation estimation (QPE) algorithms were obtained, including $\mathrm{R}\left(\mathrm{Z}_{\mathrm{H}}\right), \mathrm{R}\left(\mathrm{Z}_{\mathrm{H}}, \mathrm{Z}_{\mathrm{DR}}\right), \mathrm{R}\left(\mathrm{K}_{\mathrm{DP}}\right)$, and $\mathrm{R}\left(\mathrm{K}_{\mathrm{DP}}, \mathrm{Z}_{\mathrm{DR}}\right)$. In order to clearly demarcate the optimal ranges of the four QPE algorithms by considering the impact of the monsoon precipitation system of South China, the optimal ranges of the four QPE algorithms were integrated together according to the characteristics of different QPE algorithms in the reflectivity-differential reflectivity $\left(Z_{H}-Z_{D R}\right)$ space distribution by reference to 8 monsoon rainfall events from 2016 to 2020 observed in Guangzhou and Yangjiang S-POL. Then, an optimal algorithm was proposed for the quantitative estimation of monsoon precipitation in South China (2DVD-SCM) using S-POL. The 2DVD-SCM was tested by comparing it with a traditional radar QPE algorithm PPS (WSR-88D Precipitation Processing System); a classical QPE algorithm CSU-HIDRO (Colorado State University-Hydrometeor Identification Rainfall Optimization) for the polarimetric radar; a piecewise fitting algorithm LPA-PFM (Piecewise Fitting Method) based on laser raindrop spectrum. The rainfall event one-by-one test results show that the 2DVD-SCM algorithm performs obviously better than the other three algorithms in most of the rainfall events. The hourly accumulated rainfalls estimated by the 2DVD-SCM algorithm are agreed well with rain gauge observations. The normalized errors (NE) and the root mean square errors (RMSE) values of 2DVD-SCM are remarkably less than the other three algorithms, and the correlation coefficient (CC) values are higher. The results of the classified rain rate test show that the NE and RMSE values of the 2DVD-SCM algorithm are the lowest in all classified rain rates. The overall evaluation results show that the 2DVD-SCM algorithm performs obviously better than the existing three algorithms and have the potential to apply in S-band polarimetric radar monsoon rainfall estimation operational system in South China.
\end{abstract}

Keywords: quantitative precipitation estimation; raindrop size distribution; monsoon rainfall in South China; S-band polarimetric radar; 2D-Video-Disdrometer

\section{Introduction}

The climate in South China is deeply affected by Asia monsoons [1]. Heavy rainfall often occurs in South China during the summer monsoon season (May to August) [2], which always leads to serious flooding and urban waterlogging. Owing to the complex spatial-temporal changes of the monsoon rainfall system in this region, it is still a great challenge to accurately estimate precipitation. Due to the high spatial and temporal 
resolution, the weather radar has obvious advantages for estimating rainfall amounts compared with other remote sensing instrumentation [3-5].

For traditional weather radar, the Z-R relationship (relation between radar reflectivity $(\mathrm{Z})$ and rain rate $(\mathrm{R})$ ) is typically a quantitative precipitation estimation (QPE) algorithm. For example, the Precipitation Processing System (PPS) algorithm of the traditional WSR88D radar Z-R relationship is widely used [6]. Comparing with traditional radar, polarimetric radar adds several variables, such as differential reflectivity factor $\left(Z_{\mathrm{DR}}\right)$, differential phase $\left(\varphi_{\mathrm{DP}}\right)$, specific differential phase $\left(\mathrm{K}_{\mathrm{DP}}\right)$, and correlation coefficient $(C \mathrm{C})[7,8]$ can provide more information about the precipitation particles size, shape, and orientation. Improving the QPE accuracy of polarimetric radar is one of the major research points in the last two decades [9-12]. Previous studies have shown that variability of the raindrop size distribution (DSD) can lead to uncertainties in the QPE results [13]. The DSDs vary with respect to rain intensity, type, and season $[14,15]$. The polarimetric radar parameters can be used to characterize the variation of DSDs. For example, the large $Z_{\mathrm{DR}}$ values indicate a big mean raindrop size. $K_{\mathrm{DP}}$ reflects both the number concentration and shape of the hydrometeors and can usually accurate estimation for heavy rainfall. These polarization variables can be used to improve the accuracy of precipitation estimation [16,17].

Due to the large variation of precipitation DSD, every single QPE algorithm has its own limitations under different conditions. For example, $\mathrm{R}\left(\mathrm{K}_{\mathrm{DP}}\right)$ and $\mathrm{R}\left(\mathrm{K}_{\mathrm{DP}}, \mathrm{Z}_{\mathrm{DR}}\right)$ algorithms usually perform well in heavy rainfall situations comparing with $R\left(Z_{H}\right)$ and $\mathrm{R}\left(\mathrm{Z}_{\mathrm{H}}, \mathrm{Z}_{\mathrm{DR}}\right)$, while the performances are opposite when rain rates are weak [18]. Therefore, a composite QPE algorithm $\mathrm{R}(\mathrm{C})$ [19] is needed to improve the accuracy of QPE. Ryzhkov et al. [20] selected different precipitation estimation relations according to the rainfall intensity calculated by $\mathrm{R}\left(\mathrm{Z}_{\mathrm{H}}\right)$, and the JPOLE composite algorithm was proposed. Cifelli et al. [21] selected different QPE algorithms through the thresholds of $Z_{\mathrm{H}}, Z_{\mathrm{DR}}$, and $\mathrm{K}_{\mathrm{DP}}$, and proposed the classic CSU-HIDRO (Colorado State University-Hydrometeor Identification Rainfall Optimization) algorithm, which has good performance in most precipitation estimation applications. In the research of precipitation estimation algorithm based on raindrop spectrum inversion, Wang et al. [22] established precipitation estimation formulas with different polarization variables by using DSDs in South China and established an optimized QPE algorithm for S-band dual polarimetric radar. Based on the laser distrometer (LPA10) in South China, Zhang et al. [23] used LPA-PFM (Piecewise Fitting Method) to improve the QPE accuracy of the S-band dual polarimetric radar. On the study of monsoon precipitation, Chen et al. [7] derived three different precipitation estimators, $R\left(Z_{H}\right)$, $\mathrm{R}\left(\mathrm{Z}_{\mathrm{H}}, \mathrm{Z}_{\mathrm{DR}}\right)$, and $\mathrm{R}\left(\mathrm{K}_{\mathrm{DP}}\right)$ by using the data of $2 \mathrm{D}$-Video-Disdrometer (2DVD) and C-band polarimetric radar in Eastern China. Based on the statistical QPE error in the $Z_{\mathrm{H}}-Z_{\mathrm{DR}}$ space, a composite QPE algorithm is constructed by combining $\mathrm{R}\left(\mathrm{Z}_{\mathrm{H}}\right), \mathrm{R}\left(\mathrm{Z}_{\mathrm{H}}, \mathrm{Z}_{\mathrm{DR}}\right)$, and $\mathrm{R}\left(\mathrm{K}_{\mathrm{DP}}\right)$ and is proven to outperform any single QPE algorithm. The thresholds of $Z_{\mathrm{H}}, Z_{\mathrm{DR}}$, and $\mathrm{K}_{\mathrm{DP}}$ in the composite QPE algorithm vary with weather systems and geographical locations. However, the relationships of $Z_{\mathrm{H}}, Z_{\mathrm{DR}}$, and $\mathrm{K}_{\mathrm{DP}}$ for monsoon rainfall in South China have yet to be addressed and lacks a composite QPE algorithm for monsoon rainfall systems in South China. All of the S-band Doppler radars in South China have been upgraded to polarimetric radars before 2021. Therefore, it is an urgent matter to establish an optimal and composite S-band polarimetric radar QPE algorithm for monsoon rainfall estimation in South China.

A new composite QPE algorithm for monsoon rainfall in South China (2DVD-SCM) is proposed based on monsoon DSD characteristics and QPE performances in the $Z_{\mathrm{H}}-Z_{\mathrm{DR}}$ distribution space, and the 2DVD-SCM has proved better than every single estimator in this study. The data and quality control are described in Section 2. The establishments of the QPE algorithm are introduced in Section 3. The performances of single and composite QPE algorithms are compared in Section 4. The QPE performances of 2DVD-SCM, PPS, LPA-PFM, and CSU-HIDRO are evaluated in Section 5. The conclusions of this study are provided in Section 6. 


\section{Data and Quality Control}

\subsection{S-Band Polarimetric Radar}

The S-band polarimetric radar data used in this study are from the GZ S-POL located at Guangzhou station and the YJ S-POL located at Yangjiang station in Guangdong Province (as shown in Figure 1). The antenna of GZ S-POL is $179 \mathrm{~m}$ above sea level and is $105.6 \mathrm{~m}$ for YJ S-POL. Both GZ S-POL and YJ S-POL were upgraded from the China New Generation Weather Radar/SA (CINRAD/SA) to polarimetric radar in March 2016. The range resolutions have been increased from 1000 to $250 \mathrm{~m}$, and have added polarimetric parameters of $Z_{\mathrm{DR}}, \varphi_{\mathrm{DP}}, \mathrm{K}_{\mathrm{DP}}$, and CC. Liu et al. [8] have given the main performance indices of the upgraded radar. Both GZ S-POL and YJ S-POL operated with the volume coverage pattern 21 mode (VCP21). The VCP21 consists of 1-elevation plan position indicator (PPI) scans between $0.5^{\circ}$ and $19.5^{\circ}$, and takes about 6 min to complete, with a $0.95^{\circ}$ beam width and a $0.25 \mathrm{~km}$ radial resolution.

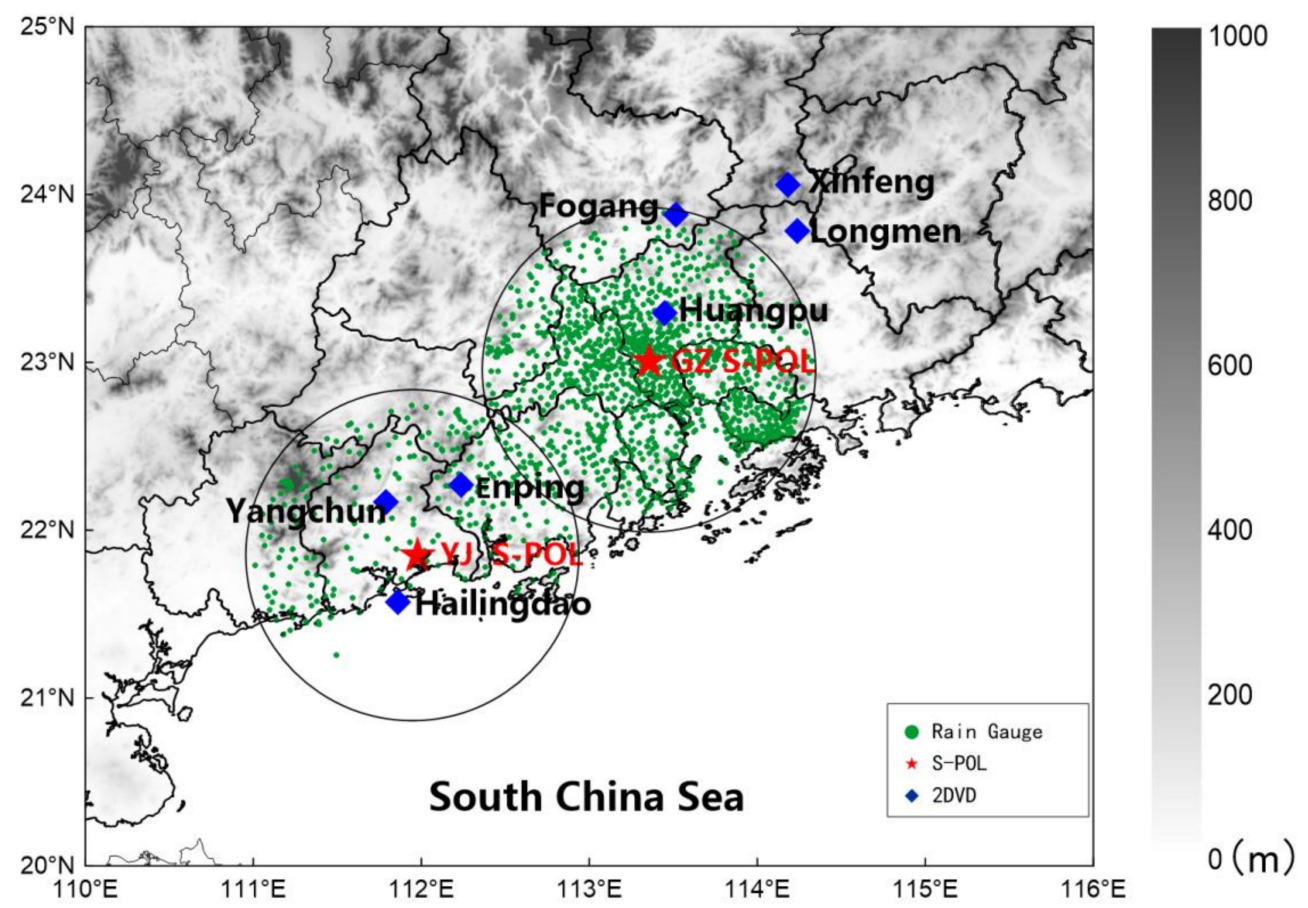

Figure 1. The red five-pointed stars represent the Locations of S-POL at Guangdong Province on the terrain heightmap. Green points show the location of the automatic weather stations within the area of radar coverage (5-100 km radius). The blue diamonds represent the 2DVD at Longmen Cloud Physics Field Experiment Base, CMA.

Obtaining high-quality polarimetric radar data is the prerequisite for accurate radar QPE. The radar data quality control (QC) procedures are similar to those in Chen et al. [7] and Huang et al. [24], which can be summarized as follows:

(1) Based on research of textural characteristics of meteorological radar echoes and nonmeteorological echoes [25,26], non-meteorological echoes such as ground clutters, biological echoes and anomalous propagation were removed under restrictive conditions including $\mathrm{SD}\left(\varphi_{\mathrm{DP}}\right)>5^{\circ}, \mathrm{SD}\left(\mathrm{Z}_{\mathrm{DR}}\right)>1 \mathrm{~dB}$ and $\mathrm{CC}<0.9$. Therefore, the interference of ground clutter to QPE can be effectively suppressed. Progressive beam broadening and stronger impact of nonuniform beam filling (NBF) are the reasons the quality of polarimetric information deteriorates with range. So, this paper selects these samples at elevations of $1.5^{\circ}$ within a range of $5-100 \mathrm{~km}$ from the radars.

(2) For $Z_{\mathrm{H}}$ and $\mathrm{Z}_{\mathrm{DR}}$, the median filter and moving average of 5 range bins along the radial direction were used to eliminate outliers and reduce random fluctuations. $Z_{\mathrm{H}}$ was effectively calibrated in the metal ball experiment [27]. The micro-raindrop technique 
was used to perorm quality control of $Z_{D R}[28,29]$. Considering that $Z_{D R}$ is closely related to $S_{N R}$ (Signal Noise Ratio), $S_{N R} \geq 15$ is used in the present study to eliminate serious random errors of $Z_{D R}$ in the low $S_{N R}$ region.

(3) In order to improve the capability for estimating strong precipitation, the present study sought to improve the quality control effect of $\varphi_{\mathrm{DP}}$ using the linear programming (LP) method [30], which was proposed by Giangrande et al. [31]. The $\varphi_{\text {DP }}$ should be cumulatively increased and $\mathrm{K}_{\mathrm{DP}}$ is not negative in the rainfall location.

\subsection{DSD Measurements}

Several 2DVDs of the Longmen Cloud Physics Field Experiment Base, CMA (China Meteorological Administration) are used to observe monsoon rainfall DSDs for deriving synthetic polarimetric radar parameters and QPE algorithms. The locations of these 2DVDs are shown in Figure 1, and the detailed information of 2DVDs has been given by Liu et al. [8]. The data quality control and processing method for the 2DVD observations are similar to those of Tokay et al. [32], Wen et al. [33], and Feng et al. [34]. Two years of 2DVD observations during summer monsoon periods from 2017 to 2018 are used in this study. For each one-minute resolution DSD data, if the total raindrops number less than 50 or the rain rate is less than $0.1 \mathrm{~mm} / \mathrm{h}$, it is considered as noise and is discarded. There were 79,122 one-minute-averaged monsoon rainfall DSD samples are available for analysis in this study.

\subsection{Rain Gauge}

The ground rain gauge observations were used to evaluate the accuracies of QPE algorithms. The rain gauge observations were taken as hourly accumulated rainfall data, and the resolution was $0.1 \mathrm{~mm}$. The hourly rainfall accumulations are divided into four categories, which are less than $10 \mathrm{~mm}, 10-20 \mathrm{~mm}, 20-50 \mathrm{~mm}$, and larger than $50 \mathrm{~mm}$.

The outliers might come from unreliable rain gauges, which should be excluded from the QPE evaluation:

(1) One of the estimated values and the observed value is null;

(2) The data of partial beam blockage (PBB) in the radial direction of the radar;

(3) The rain gauge was eliminated according to the threshold value and time consistency checking method proposed by Wu et al. [35] and the spatial continuity of accumulated rainfall testing by speckle filtering [36].

\subsection{Monsoon Rainfall Events}

To evaluate the performance of the QPE algorithms, eight wide-range monsoon rainstorm processes that occurred from 2016 to 2020 were selected. As shown in Figure 1, there are 1350 rain gauges within the GZ S-POL and YJ S-POL radar coverage areas for these eight monsoon rainfall events. The detail of these eight monsoon rainfall events and rain gauge data are given in Table 1.

Table 1. A list of the eight monsoon rainfall events analyzed in this study.

\begin{tabular}{|c|c|c|c|c|c|c|}
\hline Event & Period (UTC) & $\begin{array}{c}\text { Total } \\
\text { Time (h) }\end{array}$ & $\begin{array}{l}\text { No. of Valued } \\
\text { Gauges }\end{array}$ & $\begin{array}{l}\text { Mean Gauge } \\
\text { Accumulation } \\
(\mathrm{mm})\end{array}$ & $\begin{array}{l}\text { Max Gauge } \\
\text { Accumulation } \\
(\mathrm{mm})\end{array}$ & $\begin{array}{l}\text { Max Gauge Hourly } \\
\text { Accumulation (mm) }\end{array}$ \\
\hline 1 & 11 July 2016 & 21 & 731 & 54.3 & 272.8 & 98.8 \\
\hline 2 & 16-19 June 2017 & 38 & 1121 & 110.9 & 405.7 & 89.6 \\
\hline 3 & 3-4 July 2017 & 21 & 206 & 69.0 & 655.9 & 104.1 \\
\hline 4 & 23-24 July 2018 & 24 & 1246 & 48.3 & 274.3 & 63.3 \\
\hline 5 & 28-31 August 2018 & 37 & 1236 & 167.7 & 614.3 & 103.5 \\
\hline 6 & 24-29 May 2019 & 92 & 1316 & 148.3 & 672.8 & 122 \\
\hline 7 & 21-22 May 2020 & 16 & 1377 & 53.5 & 402.2 & 140.8 \\
\hline 8 & 30 May-2 June 2020 & 24 & 1221 & 77.5 & 646.1 & 98.1 \\
\hline
\end{tabular}




\subsection{Assessing the Accuracy of QPE Algorithms}

The normalized error (NE), root mean square error (RMSE), and CC between the estimated value and the observed value were respectively calculated (Equations (1)-(3)), and the three evaluations indicators were used to evaluate the QPE algorithm involved in the present study. They are defined as [5,7,12]:

$$
\begin{gathered}
\mathrm{NE}=\frac{\frac{1}{\mathrm{~N}} \sum_{\mathrm{i}=1}^{\mathrm{N}}\left|\mathrm{R}_{\text {Radar }, \mathrm{i}}-\mathrm{R}_{\text {Gauge, } \mathrm{i}}\right|}{\overline{\mathrm{R}_{\text {Gauge }}}} \times 100 \% \\
\mathrm{RMSE}=\sqrt{\frac{1}{\mathrm{~N} \sum_{\mathrm{i}=1}^{\mathrm{N}}\left(\mathrm{R}_{\text {Radar }, \mathrm{i}}-\mathrm{R}_{\text {Gauge }, \mathrm{i}}\right)^{2}}} \\
\left.\sqrt{\sum_{\mathrm{i}=1}^{\mathrm{N}}\left(\mathrm{R}_{\text {Gauge }, \mathrm{i}}-\overline{\mathrm{R}_{\text {Gauge }}}\right)^{2} \sum_{\mathrm{i}=1}^{\mathrm{N}}\left(\mathrm{R}_{\text {Gaudar }, \mathrm{i}}-\overline{\mathrm{R}_{\text {Radar }}}\right)^{2}}-\overline{\mathrm{R}_{\text {Gauge }}}\right)\left(\mathrm{R}_{\text {Radar }, \mathrm{i}}-\overline{\mathrm{R}_{\text {Radar }}}\right)
\end{gathered}
$$

where $R_{\text {Radar }}$ represents estimated precipitation, $R_{\text {Gauge }}$ represents observed precipitation, and $\mathrm{N}$ represents the number of samples. Every sample contains the observed value and estimated value. The NE represents the deviation between the estimated value and the observed value. The smaller the deviation, the higher the accuracy and credibility of precipitation estimation. The RMSE reflects the extent to which the estimated value deviates from the observed value. The smaller this RMSE, the more concentrated the deviation distribution, and the higher the stability of the algorithm. The CC represents the correlation extent between the estimated value and the observed value. The closer CC is to 1 , the higher the correlation.

\section{Establish QPE Algorithm}

\subsection{QPE Algorithm Based on DSD Measurements}

Based on the S-band polarimetric radar simulator developed by Wang et al. [37], the 2DVD observations of monsoon rainfall DSDs in South China are used to calculate $Z_{\mathrm{H}}$, $\mathrm{Z}_{\mathrm{DR}}$, and $\mathrm{K}_{\mathrm{DP}}$. Four rainfall estimators, $\mathrm{R}\left(\mathrm{Z}_{\mathrm{H}}\right), \mathrm{R}\left(\mathrm{Z}_{\mathrm{H}}, \mathrm{Z}_{\mathrm{DR}}\right), \mathrm{R}\left(\mathrm{K}_{\mathrm{DP}}\right)$, and $\mathrm{R}\left(\mathrm{Z}_{\mathrm{DR}}, \mathrm{K}_{\mathrm{DP}}\right)$ are derived from these $2 \mathrm{DVD}$ datasets. The disdrometer-based $\mathrm{R}\left(\mathrm{Z}_{\mathrm{H}}\right)$ relation of monsoon rainfall in South China is

$$
\mathrm{R}\left(\mathrm{Z}_{\mathrm{H}}\right)=0.0474 \mathrm{Z}_{\mathrm{H}}^{0.6141}
$$

The best-fit equation of $\mathrm{R}\left(\mathrm{Z}_{\mathrm{H}}, \mathrm{Z}_{\mathrm{DR}}\right)$ derived from the 2DVD dataset for monsoon rainfall in South China is

$$
\mathrm{R}\left(\mathrm{Z}_{\mathrm{H}}, \mathrm{Z}_{\mathrm{DR}}\right)=0.00217 \mathrm{Z}_{\mathrm{H}}{ }^{0.9181} \mathrm{Z}_{\mathrm{DR}}{ }^{-1.1912}
$$

For the $\mathrm{R}\left(\mathrm{K}_{\mathrm{DP}}\right)$ relation, the fitted formula is

$$
\mathrm{R}\left(\mathrm{K}_{\mathrm{DP}}\right)=53.152 \mathrm{~K}_{\mathrm{DP}}{ }^{0.8485}
$$

The fitted $R\left(K_{D P}, Z_{D R}\right)$ relationship is expressed as

$$
\mathrm{R}\left(\mathrm{K}_{\mathrm{DP}}, \mathrm{Z}_{\mathrm{DR}}\right)=97.486 \mathrm{~K}_{\mathrm{DP}}{ }^{0.9837} 10^{-0.2078 \mathrm{Z}_{\mathrm{DR}}}
$$

The scatterplots of the rain rate obtained from four rainfall Estimators (4)-(7) versus the 2DVD observed rain rates are given in Figure 2a-d. These are the performances of the QPE algorithms during the "ideal conditions". As shown in Figure 2, the $\mathrm{R}\left(\mathrm{Z}_{\mathrm{H}}\right)$ has the lowest CC and the largest RMSE and NE values, suggesting that it is the worst of all four algorithms. $R\left(Z_{H}, Z_{D R}\right)$ performs better than $R\left(Z_{H}\right)$. The error of $R\left(K_{D P}\right)$ and $R\left(Z_{D R}, K_{D P}\right)$ 
are significantly smaller than that of $\mathrm{R}\left(\mathrm{Z}_{\mathrm{H}}\right)$ and $\mathrm{R}\left(\mathrm{Z}_{\mathrm{H}}, \mathrm{Z}_{\mathrm{DR}}\right)$. In particular, $\mathrm{R}\left(\mathrm{Z}_{\mathrm{DR}}, \mathrm{K}_{\mathrm{DP}}\right)$ has the lowest RMSE and NE.
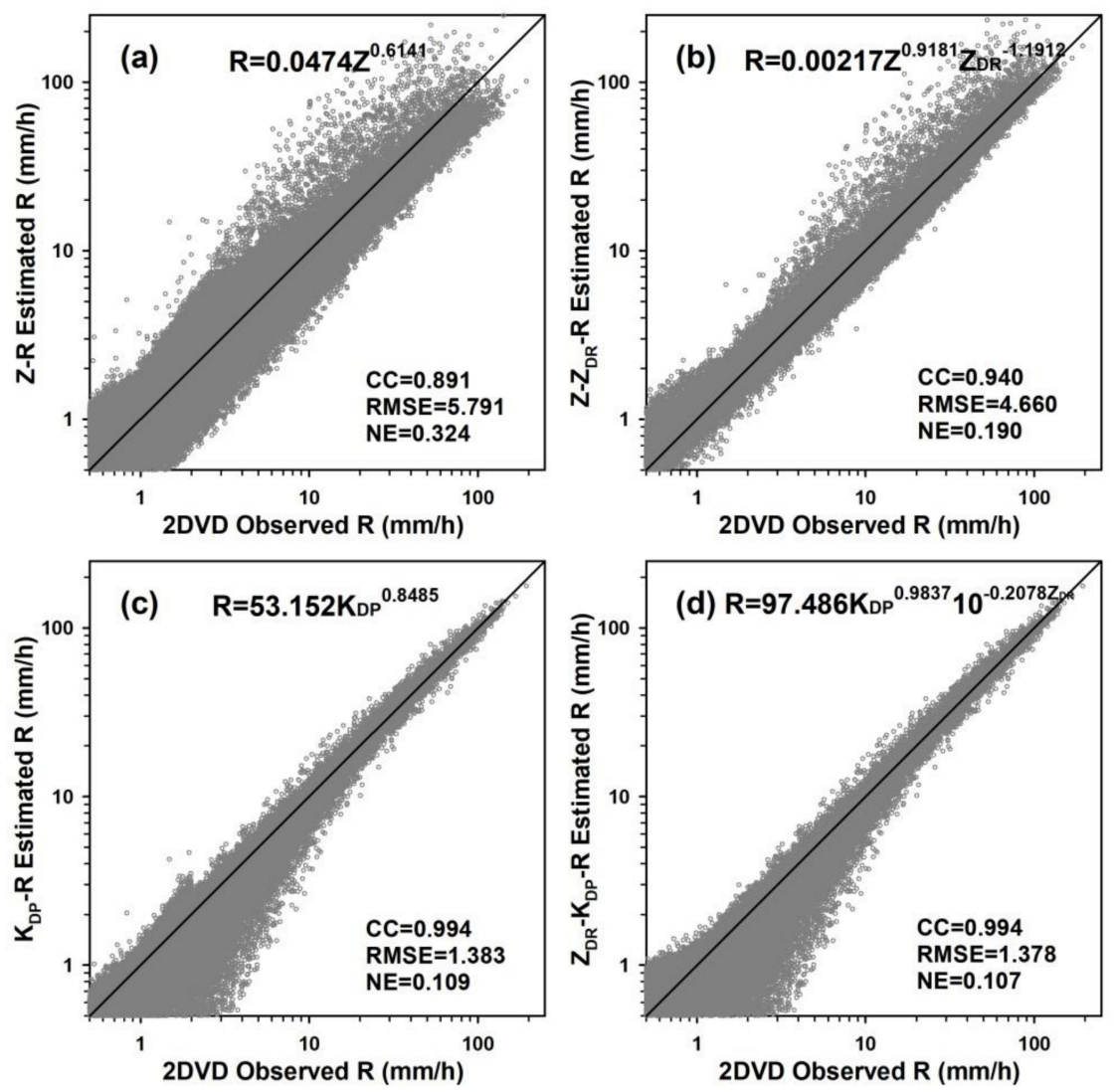

Figure 2. Scatterplot of rain rate retrieved from (a) $R\left(Z_{H}\right)$, (b) $R\left(Z_{H}, Z_{D R}\right)$, (c) $R\left(K_{D P}\right)$, and (d) $R\left(K_{D P}\right.$, $\left.Z_{\mathrm{DR}}\right)$ vs. the directly observed rain rate from the 2DVDs during summer monsoon periods from 2017 to 2018 .

\subsection{QPE Performance in $Z_{H^{-}} Z_{D R}$ Space}

The analysis of Chen et al. [7] shows that the rainfall estimators have different QPE performances in different $\mathrm{Z}_{\mathrm{H}}-\mathrm{Z}_{\mathrm{DR}}$ spaces. Following this method, the mean NE distributions of the four QPE algorithms in $Z_{\mathrm{H}}-Z_{\mathrm{DR}}$ space were revealed based on the data from two S-POL radars and the rain gauges according to the selected eight monsoon rainfall events in South China, as shown in Figure 3. The average spatial scale is $0.25 \mathrm{~km}$ (range bin) $\times 1^{\circ}$ (azimuth), and the temporal scale is $1 \mathrm{~h}$. The data points with an hourly rain rate of less than $0.1 \mathrm{~mm} / \mathrm{h}$ are disregarded. The coordinate interval of $Z_{\mathrm{H}}$ and $\mathrm{Z}_{\mathrm{DR}}$ is $2 \mathrm{dBZ}$ and $0.2 \mathrm{~dB}$ in this analysis, while the NEs of QPE are averaged and the filled color represents the NE values.

The distribution characteristics of the NE values of the four QPE algorithms in $Z_{H^{-}}-Z_{D R}$ space were obtained, as shown in Figure 3. There are obvious differences among each QPE algorithm. When $\mathrm{Z}_{\mathrm{H}}<42 \mathrm{dBZ}$ and $\mathrm{Z}_{\mathrm{DR}}<1.8 \mathrm{~dB}$ or $\mathrm{Z}_{\mathrm{H}}<38 \mathrm{dBZ}$, the $\mathrm{NE}$ of $\mathrm{R}\left(\mathrm{Z}_{\mathrm{H}}\right)$ is lower than that of the rest three QPE algorithms. The NE increases rapidly with increases in $Z_{H}$ and $Z_{D R}$. The $N E$ of $R\left(Z_{H}, Z_{D R}\right)$ in the region of $38 \mathrm{dBZ}<Z_{H}<42 \mathrm{dBZ}$ and $Z_{D R}>1.8 \mathrm{~dB}$ are better than those of $R\left(Z_{H}\right)$, suggesting that the performance of $R\left(Z_{H}\right)$ is susceptible to the DSD of precipitation particles, especially when the $Z_{D R}$ value is large. With the further increase of $\mathrm{Z}_{\mathrm{H}}$, the shortcomings of $\mathrm{R}\left(\mathrm{Z}_{\mathrm{H}}\right)$ and $\mathrm{R}\left(\mathrm{Z}_{\mathrm{H}}, \mathrm{Z}_{\mathrm{DR}}\right)$ become more prominent. In general, when $Z_{H}>42 \mathrm{dBZ}$, the performance of $\mathrm{R}\left(\mathrm{K}_{\mathrm{DP}}\right)$ and $\mathrm{R}\left(\mathrm{K}_{\mathrm{DP}}, \mathrm{Z}_{\mathrm{DR}}\right)$ is significantly better than that of $\mathrm{R}\left(\mathrm{Z}_{\mathrm{H}}\right)$ and $\mathrm{R}\left(\mathrm{Z}_{\mathrm{H}}, \mathrm{Z}_{\mathrm{DR}}\right)$. When $\mathrm{Z}_{\mathrm{H}}>42 \mathrm{dBZ}$ and $\mathrm{Z}_{\mathrm{DR}}<1.0 \mathrm{~dB}$, the $\mathrm{NE}$ of $\mathrm{R}\left(\mathrm{K}_{\mathrm{DP}}\right)$ are better than those of $\mathrm{R}\left(\mathrm{K}_{\mathrm{DP}}, \mathrm{Z}_{\mathrm{DR}}\right)$. With the increase of $Z_{\mathrm{DR}}$, the performance superiority of $\mathrm{R}\left(\mathrm{K}_{\mathrm{DP}}, \mathrm{Z}_{\mathrm{DR}}\right)$, which contains an additional polarization variable, is gradually 
demonstrated. In heavy rainfall events of $Z_{H}>42 \mathrm{dBZ}$ and $Z_{\mathrm{DR}}>1.0 \mathrm{~dB}$, the $\mathrm{NE}$ of $\mathrm{R}\left(\mathrm{K}_{\mathrm{DP}}\right.$, $\left.\mathrm{Z}_{\mathrm{DR}}\right)$ is slightly better than that of $\mathrm{R}\left(\mathrm{K}_{\mathrm{DP}}\right)$.
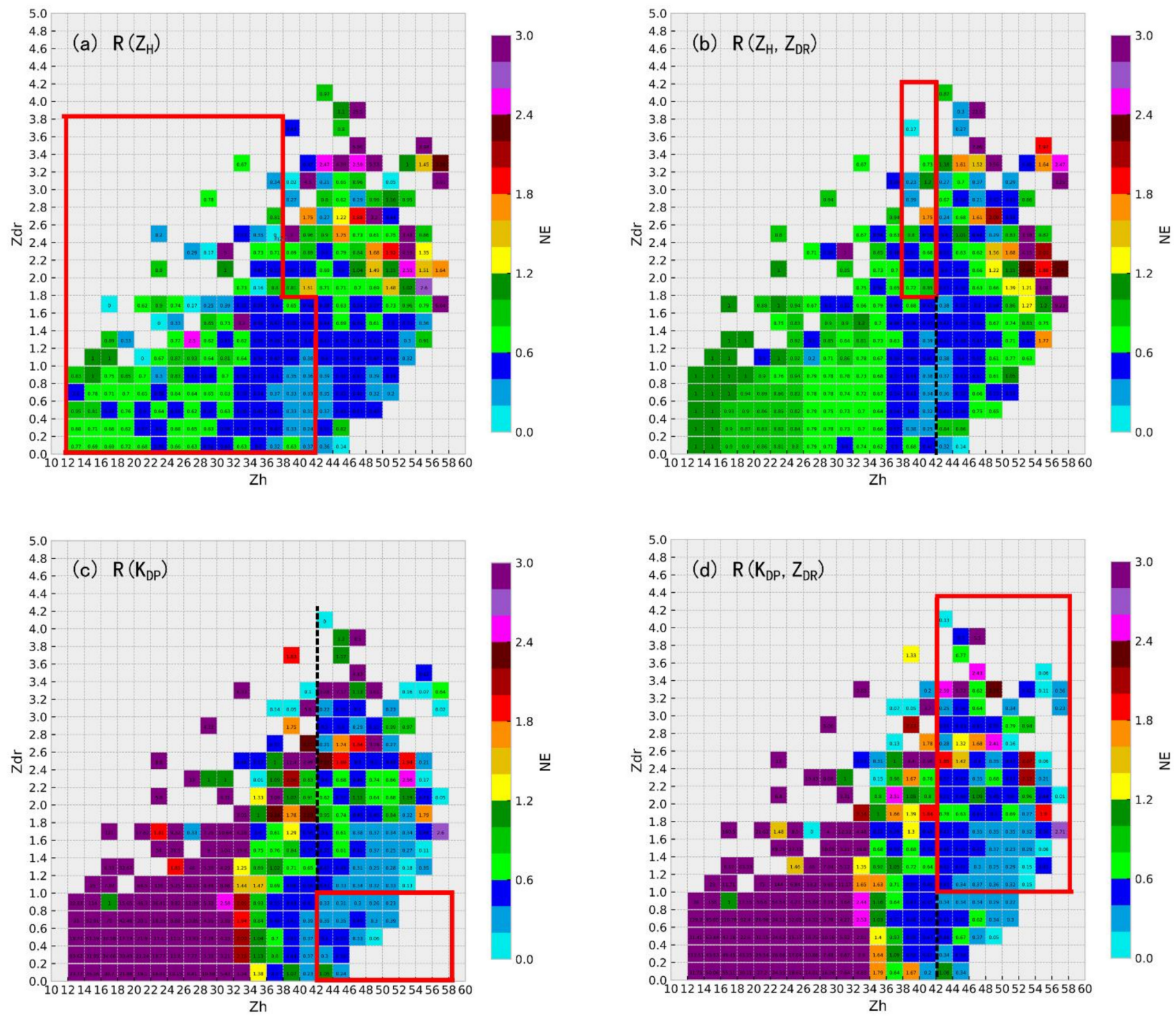

Figure 3. The hourly QPE normalized error of $(\mathbf{a}) \mathrm{R}\left(\mathrm{Z}_{\mathrm{H}}\right)$, (b) $\mathrm{R}\left(\mathrm{Z}_{\mathrm{H}}, \mathrm{Z}_{\mathrm{DR}}\right)$, (c) $\mathrm{R}\left(\mathrm{K}_{\mathrm{DP}}\right)$, and $(\mathbf{d}) \mathrm{R}\left(\mathrm{K}_{\mathrm{DP}}, \mathrm{Z}_{\mathrm{DR}}\right)$ for all eight monsoon rainfall events in $Z_{\mathrm{H}}-Z_{\mathrm{DR}}$ space. Red frames represent the optimal thresholds ranges of four rainfall estimators to calculate composite QPE algorithm $(\mathrm{R}(\mathrm{C}))$.

The performances of the above four QPE algorithms indicate that each algorithm has a different advantage:

(1) The performance of $\mathrm{R}\left(\mathrm{Z}_{\mathrm{H}}\right)$ is relatively stable in the case of weak echo. With the enhancement of $Z_{\mathrm{H}}$ and the increase of $Z_{\mathrm{DR}}$, the QPE accuracy becomes unstable due to the DSD of precipitation particles, so it is inapplicable to strong precipitation estimation;

(2) Compared with $R\left(Z_{H}\right)$, the polarization variable $Z_{D R}$ is introduced into $R\left(Z_{H}, Z_{D R}\right)$, which can reduce the error caused by big raindrops to a certain extent;

(3) The performance of $\mathrm{R}\left(\mathrm{K}_{\mathrm{DP}}\right)$ and $\mathrm{R}\left(\mathrm{K}_{\mathrm{DP}}, \mathrm{Z}_{\mathrm{DR}}\right)$ is better than that of $\mathrm{R}\left(\mathrm{Z}_{\mathrm{H}}\right)$ and $\mathrm{R}\left(\mathrm{Z}_{\mathrm{H}}\right.$, $\left.Z_{\mathrm{DR}}\right)$ in heavy rainfall. When the concentration of big raindrops is higher, the performance of $\mathrm{R}\left(\mathrm{K}_{\mathrm{DP}}, \mathrm{Z}_{\mathrm{DR}}\right)$ is slightly better than that of $\mathrm{R}\left(\mathrm{K}_{\mathrm{DP}}\right)$. 


\subsection{Establishment of the 2DVD-SCM Composite Estimation Algorithm}

According to Section 3.2, a new composite QPE algorithm (R(C)) named 2DVD-SCM has been proposed by integrating optimal ranges of the four rainfall estimators in $\mathrm{Z}_{\mathrm{H}^{-}}$ $Z_{\mathrm{DR}}$ space. In other words, the threshold of $\mathrm{Z}_{\mathrm{H}}$ and $\mathrm{Z}_{\mathrm{DR}}$ was determined according to the minimum error of the composite algorithms in the $\mathrm{Z}_{\mathrm{H}}-\mathrm{Z}_{\mathrm{DR}}$ space. The flowchart descriptions of the 2DVD-SCM algorithm are shown in Figure 4.

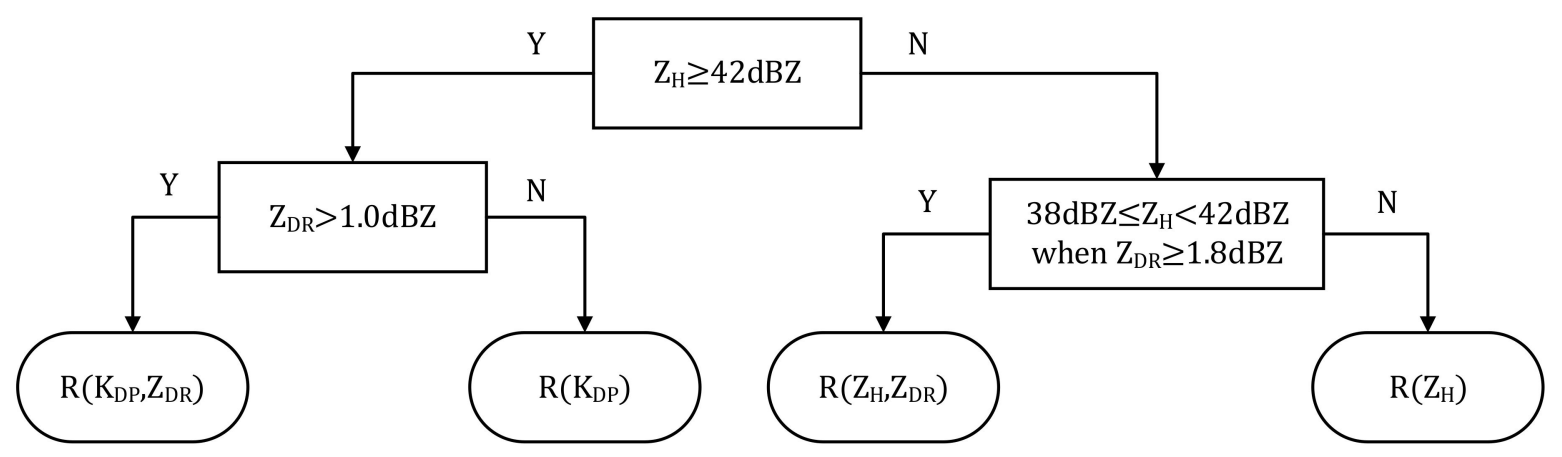

Figure 4. Flowchart description of the 2DVD-SCM QPE algorithm.

\section{Comparison of the Single and Composite QPE Algorithms}

\subsection{Typical Rainfall Event}

A continuous monsoon rainfall event that occurred from the 24 to 27 May 2019 was selected as a typical case to evaluate the detailed performance of $R\left(Z_{H}\right), R\left(Z_{H}, Z_{D R}\right)$, $\mathrm{R}\left(\mathrm{K}_{\mathrm{DP}}\right), \mathrm{R}\left(\mathrm{K}_{\mathrm{DP}}, \mathrm{Z}_{\mathrm{DR}}\right)$, and $\mathrm{R}(\mathrm{C})$. There are 69 rain gauge stations that observed hourly rainfall accumulation in excess of $40 \mathrm{~mm}$ in western Guangdong Province during this event. The total rainfall of eight stations is more than $400 \mathrm{~mm}$. In this study, the spatial distribution of bias ratio ( $\mathrm{R}_{\mathrm{QPE}} / \mathrm{R}_{\mathrm{GAUGE}}$ ) is used to test the estimation effect of each QPE algorithm. The bias ratio of $R_{\mathrm{QPE}} / \mathrm{R}_{\mathrm{GAUGE}}$ is given in Figure $5 \mathrm{a}-\mathrm{i}$. If the ratio is greater than 1 , it is displayed by a cold tone and indicates that the estimated value is higher than the observed value. If the ratio is less than 1 , it is displayed by a warm tone and indicates that the estimated value is lower than the actual value. When the ratio is close to 1 , it means that the estimation performance is excellent. In general, $\mathrm{R}\left(\mathrm{Z}_{\mathrm{H}}\right)$ would overestimate the rainfall. $\mathrm{R}\left(\mathrm{Z}_{\mathrm{H}}, \mathrm{Z}_{\mathrm{DR}}\right), \mathrm{R}\left(\mathrm{K}_{\mathrm{DP}}\right), \mathrm{R}\left(\mathrm{K}_{\mathrm{DP}}, \mathrm{Z}_{\mathrm{DR}}\right)$ would underestimate the rainfall. The $\mathrm{R}(\mathrm{C})$ estimate results agree well with observed rainfall. With regard to the scatterplots of radar QPEs versus gauge observation in Figure $5 b, d, f, h, j$, the NE and RMSE values of $R(C)$ are the lowest, and CC is the highest, which indicates the performance of $R(C)$ is the best in this rainfall event.

\subsection{All Rainfall Events}

The evaluated results of QPE in every rainfall event for $R\left(Z_{H}\right), R\left(Z_{H}, Z_{D R}\right), R\left(K_{D P}\right)$, $\mathrm{R}\left(\mathrm{K}_{\mathrm{DP}}, \mathrm{Z}_{\mathrm{DR}}\right)$, and $\mathrm{R}(\mathrm{C})$ algorithms in GZ S-POL and YJ S-POL are given in Table 2. The NE and RMSE values of $R(C)$ are the lowest in all eight rainfall events, and the CC values are the highest except in the 8th event. Scatterplots of these five QPE algorithms estimated and gauge-observed hourly rainfall is shown in Figure 6. The $\mathrm{R}\left(\mathrm{Z}_{\mathrm{H}}, \mathrm{Z}_{\mathrm{DR}}\right)$ estimator has the worst performances, and the data scatter is the largest among all five estimators. The NE, RMSE, and CC values are $45.91 \%, 7.317 \mathrm{~mm}$, and 0.834 , respectively (Figure $6 \mathrm{~b}$ ). The $\mathrm{R}(\mathrm{C}$ ) estimator provides the best agreement with the rain gauge observations. $R(C)$ performs the best with an NE of 32.62\%, an RMSE of $4.766 \mathrm{~mm}$, and a CC of 0.911 in all rainfall events. 

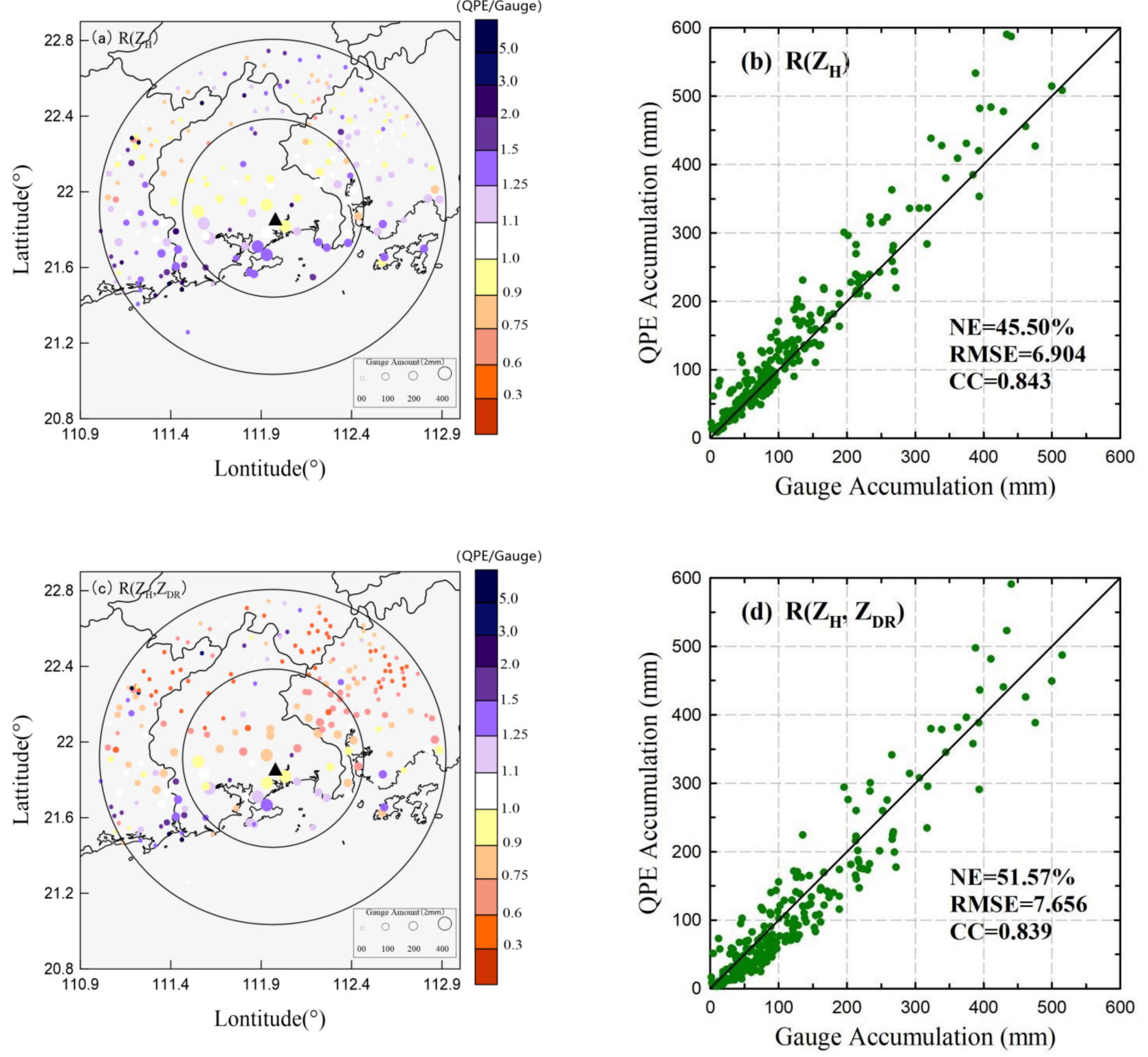

Figure 5. Cont. 

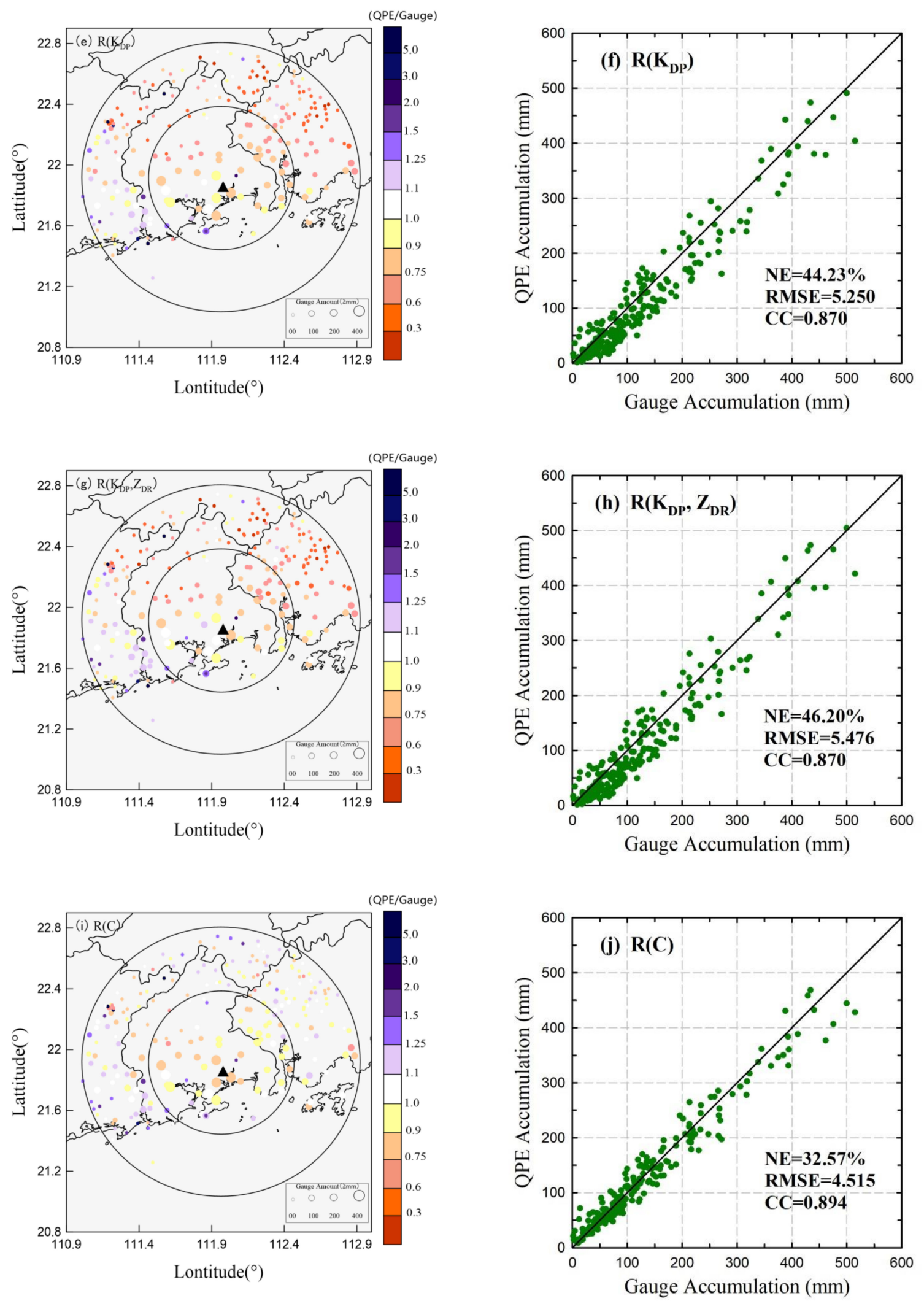

Figure 5. Comparison of $Y J$ S-POL $Q P E$ results using $R\left(Z_{H}\right), R\left(Z_{H}, Z_{D R}\right), R\left(K_{D P}\right), R\left(K_{D P}, Z_{D R}\right)$, and $R(C)$ with rain gauge observations during monsoon rainfall event 6 . The size of the circles in $(\mathbf{a}, \mathbf{c}, \mathbf{e}, \mathbf{g}, \mathbf{i})$ indicate the rain gauge-observed accumulate rainfall, and the colors show the bias ratios $\left(=R_{\mathrm{QPE}} / \mathrm{R}_{\mathrm{RG}}\right)$ between the QPES and rain gauge observations. Scatterplots in $(\mathbf{b}, \mathbf{d}, \mathbf{f}, \mathbf{h}, \mathbf{j})$ show the QPE results vs the rain gauge observations. 
Table 2. Evaluated statistical values for each rainfall relation of the eight monsoon rainfall events.

\begin{tabular}{|c|c|c|c|c|c|c|}
\hline \multirow{2}{*}{ Event } & \multirow{2}{*}{ Statistical Values } & \multicolumn{5}{|c|}{ QPE Relation } \\
\hline & & $\mathbf{R}\left(\mathrm{Z}_{\mathrm{H}}\right)$ & $R\left(Z_{H}, Z_{D R}\right)$ & $\mathbf{R}\left(\mathbf{K}_{\mathrm{DP}}\right)$ & $\mathrm{R}\left(\mathrm{K}_{\mathrm{DP}}, \mathrm{Z}_{\mathrm{DR}}\right)$ & $\mathrm{R}(\mathrm{C})$ \\
\hline \multirow{3}{*}{1} & NE (\%) & 45.74 & 44.16 & 57.8 & 63.43 & 37.05 \\
\hline & RMSE (mm) & 7.166 & 6.751 & 8.750 & 10.573 & 5.330 \\
\hline & $\mathrm{CC}$ & 0.833 & 0.829 & 0.764 & 0.712 & 0.884 \\
\hline \multirow{3}{*}{2} & NE $(\%)$ & 32.15 & 44.03 & 43.77 & 44.82 & 31.22 \\
\hline & RMSE (mm) & 5.061 & 5.927 & 5.701 & 5.916 & 4.855 \\
\hline & $\mathrm{CC}$ & 0.858 & 0.845 & 0.856 & 0.854 & 0.874 \\
\hline \multirow{3}{*}{3} & NE (\%) & 28.31 & 35.84 & 33.21 & 33.52 & 24.95 \\
\hline & RMSE (mm) & 5.866 & 6.474 & 5.642 & 5.713 & 4.780 \\
\hline & $\mathrm{CC}$ & 0.908 & 0.904 & 0.927 & 0.925 & 0.945 \\
\hline \multirow{3}{*}{4} & NE (\%) & 39.27 & 51.82 & 45.8 & 49.44 & 36.37 \\
\hline & RMSE (mm) & 5.032 & 6.292 & 6.631 & 7.869 & 4.553 \\
\hline & $\mathrm{CC}$ & 0.867 & 0.835 & 0.723 & 0.674 & 0.868 \\
\hline \multirow{3}{*}{5} & NE (\%) & 47.28 & 64.49 & 56.41 & 63.48 & 41.29 \\
\hline & RMSE (mm) & 5.762 & 7.126 & 7.477 & 9.685 & 4.647 \\
\hline & $\mathrm{CC}$ & 0.845 & 0.820 & 0.739 & 0.663 & 0.881 \\
\hline \multirow{3}{*}{6} & NE (\%) & 46.82 & 45.44 & 42.24 & 45.52 & 34.43 \\
\hline & RMSE (mm) & 6.821 & 7.613 & 5.790 & 6.596 & 4.635 \\
\hline & $\mathrm{CC}$ & 0.854 & 0.839 & 0.853 & 0.831 & 0.894 \\
\hline \multirow{3}{*}{7} & NE (\%) & 34.40 & 35.63 & 31.64 & 32.49 & 28.06 \\
\hline & RMSE (mm) & 7.227 & 8.229 & 6.009 & 6.211 & 5.516 \\
\hline & $\mathrm{CC}$ & 0.913 & 0.903 & 0.935 & 0.936 & 0.944 \\
\hline \multirow{3}{*}{8} & NE (\%) & 46.89 & 51.2 & 36 & 37.75 & 32.8 \\
\hline & RMSE (mm) & 7.143 & 7.963 & 4.817 & 5.062 & 4.556 \\
\hline & CC & 0.824 & 0.802 & 0.912 & 0.915 & 0.91 \\
\hline
\end{tabular}

The evaluations in different hourly accumulated rainfall classes are given in Figure 7. The results show that the NE and RMSE values of $\mathrm{R}\left(\mathrm{K}_{\mathrm{DP}}\right)$ and $\mathrm{R}\left(\mathrm{K}_{\mathrm{DP}}, \mathrm{Z}_{\mathrm{DR}}\right)$ are obviously higher than other estimators when the rain rate is less than $10 \mathrm{~mm} / \mathrm{h}$, and the $\mathrm{R}\left(\mathrm{K}_{\mathrm{DP}}, \mathrm{Z}_{\mathrm{DR}}\right)$ perform worst in this class. When the rain rate is higher than $10 \mathrm{~mm} / \mathrm{h}$, the errors of $\mathrm{R}\left(\mathrm{Z}_{\mathrm{H}}\right)$ and $\mathrm{R}\left(\mathrm{Z}_{\mathrm{H}}, \mathrm{Z}_{\mathrm{DR}}\right)$ are larger than other estimators, especially for $\mathrm{R}\left(\mathrm{Z}_{\mathrm{H}}, \mathrm{Z}_{\mathrm{DR}}\right)$. The $\mathrm{NE}$ and RMSE values of $R(C)$ are the lowest, and $C C$ is the highest among the five estimators in every hourly accumulation class, which proves that the $R(C)$ algorithm has the best performances in all rain rate classes. These indicate the improvement method of $R(C)$ used in this study is useful. 

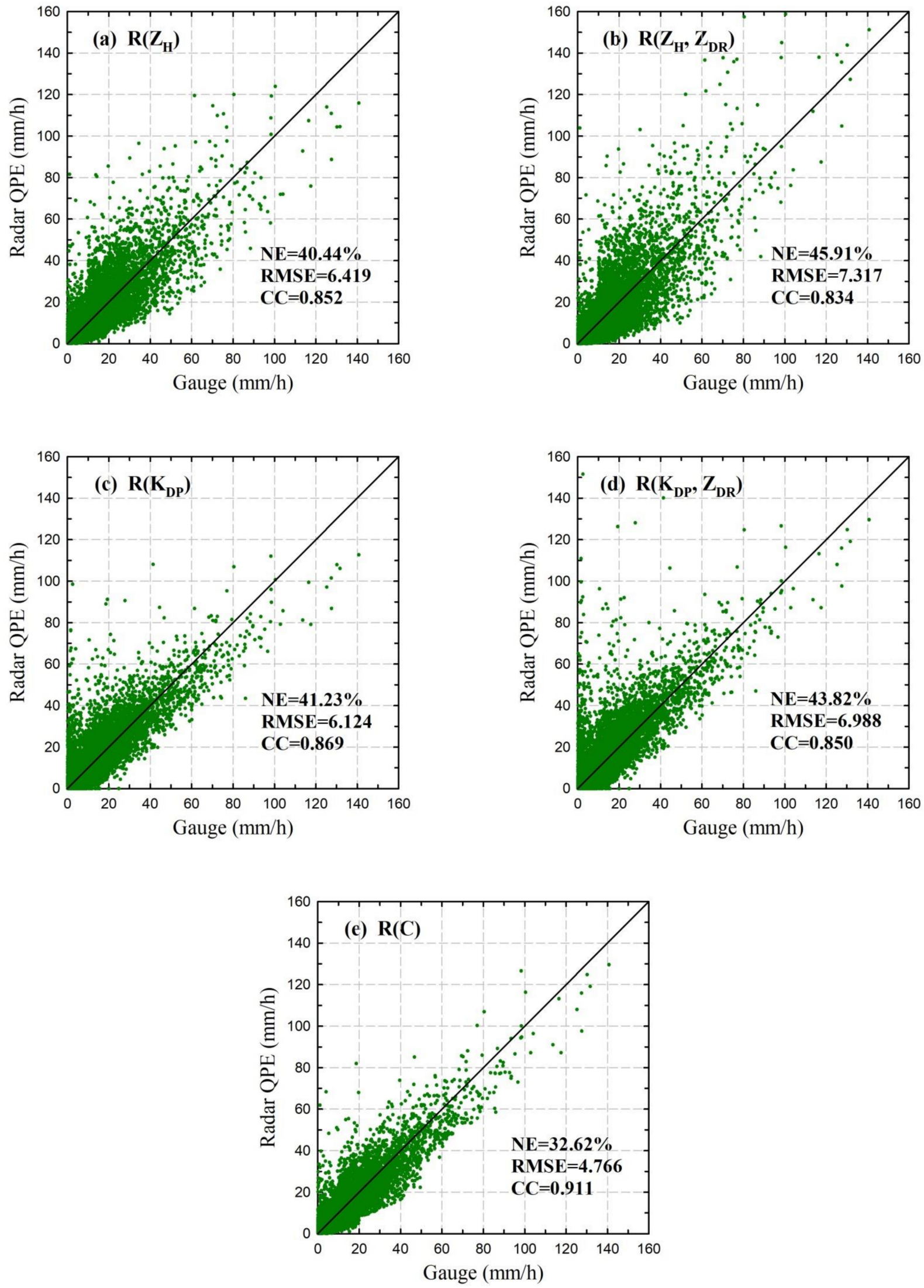

Figure 6. Scatterplots show estimated hourly rainfall from (a) $R\left(Z_{H}\right)$, (b) $R\left(Z_{H}, Z_{D R}\right)$, (c) $R\left(K_{D P}\right)$, (d) $R\left(K_{D P}, Z_{D R}\right)$, and (e) $R(C)$ compared with rain gauge observations for all eight rainfall events. 

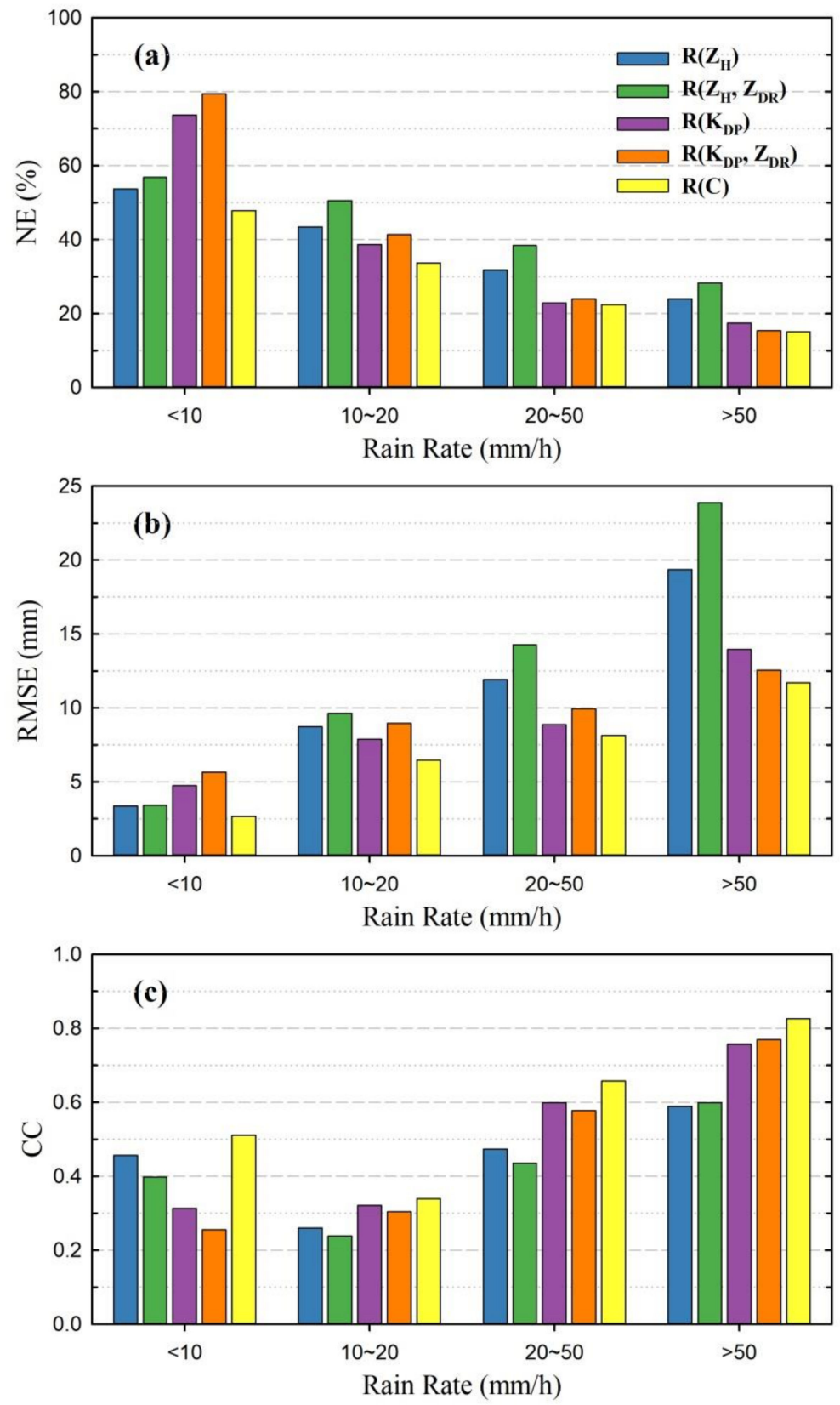

Figure 7. Bar graphs showing (a) NE (\%), (b) RMSE (mm/h) and (c) CC(non-dimensional) obtained from rainfall estimator of $\mathrm{R}\left(\mathrm{Z}_{\mathrm{H}}\right), \mathrm{R}\left(\mathrm{Z}_{\mathrm{H}}, \mathrm{Z}_{\mathrm{DR}}\right), \mathrm{R}\left(\mathrm{K}_{\mathrm{DP}}\right), \mathrm{R}\left(\mathrm{K}_{\mathrm{DP}}, \mathrm{Z}_{\mathrm{DR}}\right)$ and $\mathrm{R}(\mathrm{C})$ for different hourly accumulation classes in all eight rainfall events.

\section{Comparison of the 2DVD-SCM QPE Algorithm with Three Typical QPE Algorithms}

In order to further examine the performance of the new proposed 2DVD-SCM QPE algorithm, three typical QPE algorithms were selected to estimate precipitation, including PPS, LPA-PFM, and CSU-HIDRO.

The evaluated results in every monsoon rainfall event for PPS, LPA-PFM, CSU-HIDRO, and 2DVD-SCM are shown in Figure 8. The NE and RMSE (CC) values of 2DVD-SCM are the lowest (highest) in seven of eight rainfall events. Among the eight events, the CSU-HIDRO algorithm performs the second-best in six events. The LPA-PFM algorithm performs the best in the No. 4 event but performs the worst in four events. Therefore, the 2DVD-SCM has the best performances in most of the rainfall events. 

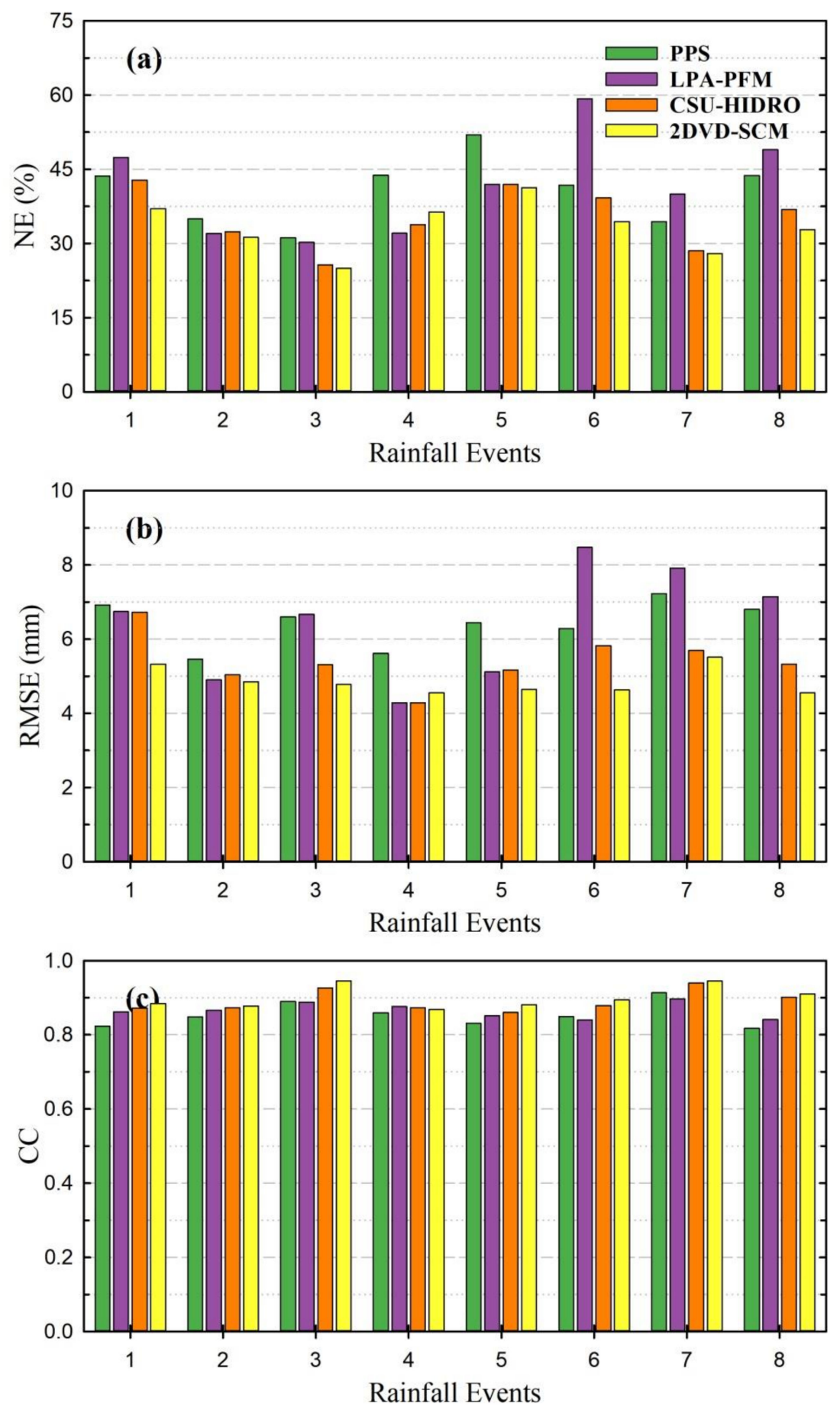

Figure 8. Bar graphs showing (a) NE (\%), (b) RMSE (mm/h), and (c) CC (non-dimensional) obtained from QPE algorithms of PPS, LPA-PFM, CSU-HIDRO, and 2DVD-SCM for eight monsoon rainfall events.

Scatterplots of these four QPE algorithms estimated and gauge-observed the hourly rainfall are given in Figure 9. The data scatters of PPS and LPA-PFM algorithms are sensitively larger than CSU-HIDRO and 2DVD-SCM algorithms. The NE and RMSE values are $43.37 \%$ and $6.938 \mathrm{~mm}$ for LPA-PFM, which are the highest among these four QPE algorithms. The NE and RMSE (CC) values of 2DVD-SCM are obviously smaller (larger) than the other three typical QPE algorithms. 

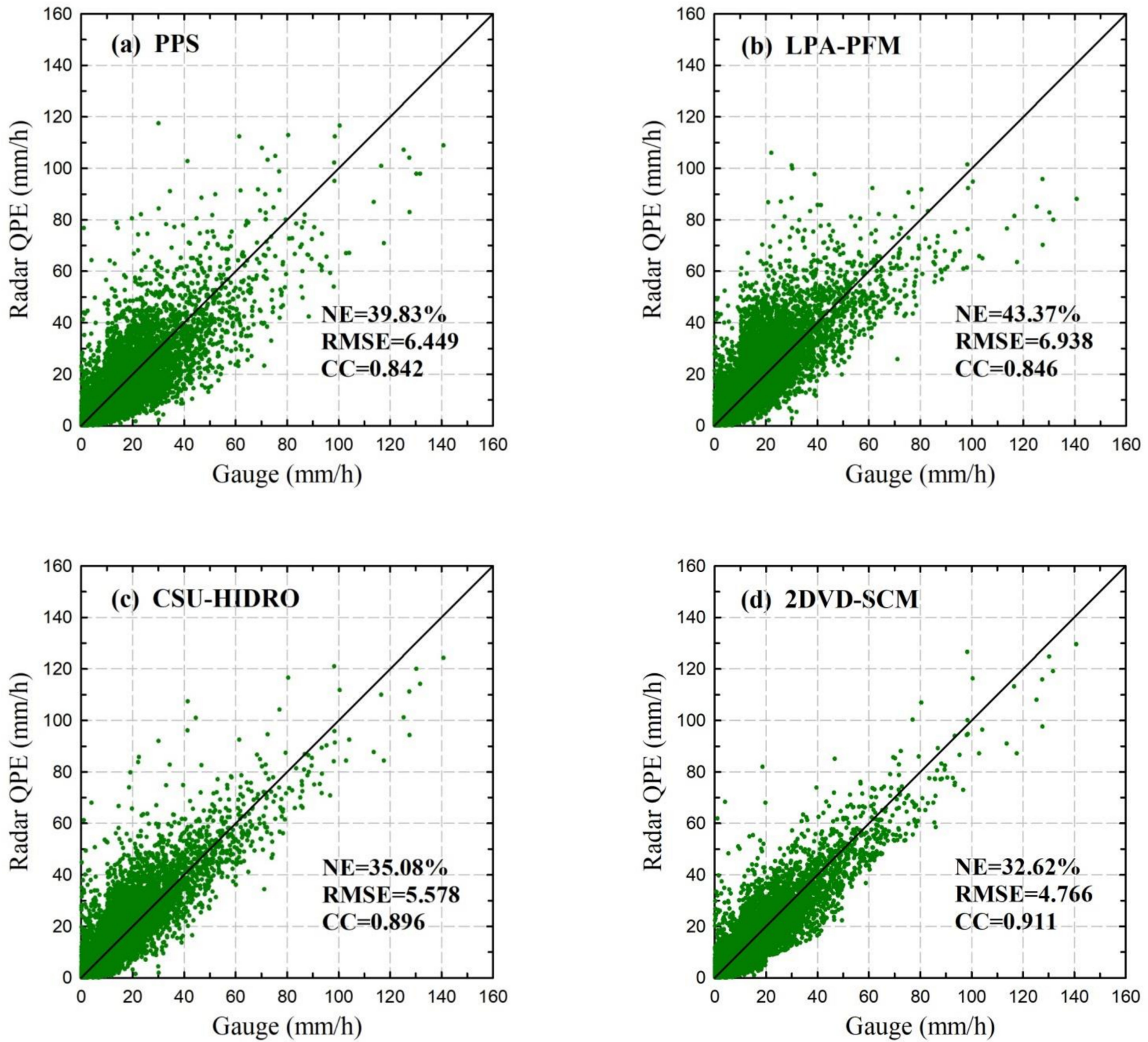

Figure 9. Scatterplots show estimated hourly rainfall from (a) PPS, (b) LPA-PFM, (c) CSU-HIDRO, and (d) 2DVD-SCM compared with rain gauge observations for all eight rainfall events.

As shown in Figure 10, the LPA-PFM algorithm has the largest NE and RMSE values when the rain rate is less than $20 \mathrm{~mm} / \mathrm{h}$. The PPS algorithm has the largest NE and RMSE values when the rain rate is above $20 \mathrm{~mm} / \mathrm{h}$ and has the lowest CC values in all hourly accumulation classes. The 2DVD-SCM algorithm has the smallest (largest) NE and RMSE (CC) values in all rain rate classes, which indicates the 2DVD-SCM algorithm has the best performances in every hourly rainfall accumulation category compared to the existed three typical QPE algorithms. 

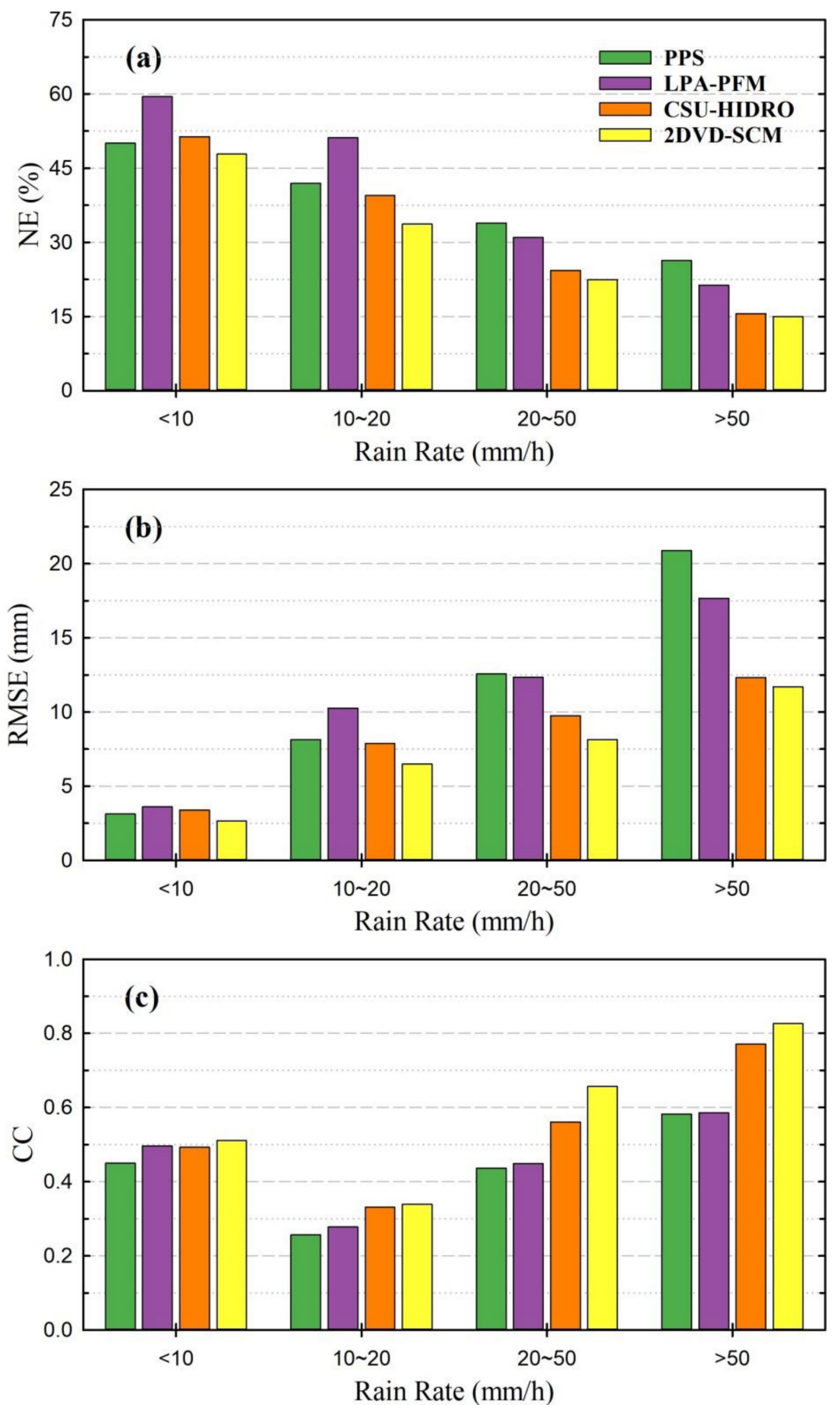

Figure 10. Bar graphs show (a) NE (\%), (b) RMSE (mm/h), and (c) CC (non-dimensional) obtained from QPE algorithms of PPS, LPA-PFM, CSU-HIDRO, and 2DVD-SCM for different hourly accumulation classes in all eight rainfall events.

Meanwhile, the PPS algorithm has better performance than LPA-PFM and CSUHIDRO algorithms when the rain rate is less than $10 \mathrm{~mm} / \mathrm{h}$. The NE and RMSE values of the CSU-HIDRO algorithm are obviously smaller than PPS and LPA-PFM algorithms when the rain rate is larger than $10 \mathrm{~mm} / \mathrm{h}$.

\section{Conclusions and Discussions}

In this paper, S-band polarimetric radar estimation for monsoon rainfall in South China was analyzed and improved by using GZ S-POL, YJ S-POL, rain gauges, and 2DVD 
observations. Four rainfall estimators of $\mathrm{R}\left(\mathrm{Z}_{\mathrm{H}}\right), \mathrm{R}\left(\mathrm{Z}_{\mathrm{H}}, \mathrm{Z}_{\mathrm{DR}}\right), \mathrm{R}\left(\mathrm{K}_{\mathrm{DP}}\right)$, and $\mathrm{R}\left(\mathrm{K}_{\mathrm{DP}}, \mathrm{Z}_{\mathrm{DR}}\right)$ were derived from 2DVD-observed DSDs during the monsoon season of 2017 and 2018 in South China. By evaluating the performance of the four rainfall estimators at $Z_{\mathrm{H}}-Z_{\mathrm{DR}}$ space in 8 monsoon rainfall events from 2016 to 2020, an optimal and composite QPE algorithm for estimating monsoon precipitation in South China (2DVD-SCM) was proposed. The performance of the 2DVD-SCM algorithm was compared with existing PPS, LPA-PFM, and CSU-HIDRO algorithms. The main conclusions of this study can be summarized as follows:

(1) In order to obtain accurate polarimetric radar QPE for monsoon rainfall systems in South China, the rainfall estimators of $\mathrm{R}\left(\mathrm{Z}_{\mathrm{H}}\right), \mathrm{R}\left(\mathrm{Z}_{\mathrm{H}}, \mathrm{Z}_{\mathrm{DR}}\right), \mathrm{R}\left(\mathrm{K}_{\mathrm{DP}}\right)$, and $\mathrm{R}\left(\mathrm{K}_{\mathrm{DP}}, \mathrm{Z}_{\mathrm{DR}}\right)$ were constructed from 2DVD DSD observations and the polarimetric radar simulator in the monsoon season of 2017 and 2018. None of the rainfall estimators can accurately estimate precipitation in all rain rate situations. The $\mathrm{R}\left(\mathrm{Z}_{\mathrm{H}}\right)$ and $\mathrm{R}\left(\mathrm{Z}_{\mathrm{H}}, \mathrm{Z}_{\mathrm{DR}}\right)$ have better performances in light rain situations compared with $\mathrm{R}\left(\mathrm{K}_{\mathrm{DP}}\right)$ and $\mathrm{R}\left(\mathrm{K}_{\mathrm{DP}}, \mathrm{Z}_{\mathrm{DR}}\right)$, but worse performances in heavy rainfall situations.

(2) The hourly rainfall estimation normalized errors of $\mathrm{R}\left(\mathrm{Z}_{\mathrm{H}}\right), \mathrm{R}\left(\mathrm{Z}_{\mathrm{H}}, \mathrm{Z}_{\mathrm{DR}}\right), \mathrm{R}\left(\mathrm{K}_{\mathrm{DP}}\right)$, and $R\left(K_{D P}, Z_{D R}\right)$ in eight monsoon events were analyzed in the $Z_{H}-Z_{D R}$ space. To improve the performance of QPE, the thresholds of $Z_{\mathrm{H}}$ and $Z_{\mathrm{DR}}$ were obtained for composite QPE algorithm R(C) (2DVD-SCM). Evaluation results show that the $R(C)$ has obviously lower (higher) NE and RMSE (CC) values compared to a single rainfall estimator.

(3) Compared with existing PPS, LPA-PFM, and CSU-HIDRO algorithms, 2DVD-SCM has the best performances in most monsoon rainfall events. The NE and RMSE (CC) values of 2DVD-SCM are as low (high) as $32.62 \%$ and $4.766 \mathrm{~mm}(0.911)$ in all eight rainfall events, which are remarkably better than the existing three QPE algorithms. The 2DVD-SCM algorithm has the best performances in each hourly rainfall accumulation category.

The analysis shows that the 2DVD-SCM algorithm is able to take advantage of the four single rainfall estimators and provide the best QPE results. Compared with the existing PPS, LPA-PFM, and CSU-HIDRO QPE algorithms, the 2DVD-SCM has the best performances in estimating monsoon rainfall in South China. The 2DVD-SCM algorithm can prove high precision QPE products. This is very useful for monsoon rainfall monitoring and forecasting, and also useful for many rainfall-related hydrologic applications, e.g., estimation of areal reduction factor and spatial classification rainfall events $[38,39]$. Nevertheless, the 2DVD-SCM QPE algorithm is only suitable for monsoon precipitation estimations in South China. It is necessary to study more types of weather systems in additional regions in the future.

Author Contributions: Conceptualization, S.H. and X.L.; Investigation, Z.G., X.L., X.C., H.Z., T.Q. and G.Z.; Supervision, S.H. and X.L.; Data analysis, Z.G., X.L., X.C., H.Z., T.Q. and G.Z.; Writingoriginal draft preparation, G.Z. and X.L.; Writing-review and editing, S.H. and X.L. All authors have read and agreed to the published version of the manuscript.

Funding: This research was supported by the Guangdong Province Key Research and Development Program (2020B0101130021), National Natural Science Foundation of China (41975138, 41905047, and 41705020), Guangdong Province Science and Technology Project (2017B020244002), and Natural Science Foundation of Guangdong Province (2019A1515010814).

Institutional Review Board Statement: Not applicable.

Informed Consent Statement: Not applicable.

Data Availability Statement: The data presented in this study are available from China Meteorological Data Service Center at the website of http:/ / data.cma.cn (accessed on 27 May 2021).

Acknowledgments: We would like to acknowledge YAN, Zhao-chao, LIU, Huang, XIAO, Xiang, LI, Jin-hong, WANG, Jian-zhuang and CHEN, Shi-dong for their assistance in the field experiment. 
Conflicts of Interest: The authors declare no conflict of interest.

\section{References}

1. Ding, Y.H. Monsoons over China; Kluwer Academic Publishers: Amsterdam, The Netherlands, 1994; 419p.

2. Luo, Y.; Zhang, R.; Wan, Q.; Wang, B.; Wong, W.K.; Hu, Z.; Jou, B.J.D.; Lin, Y.; Johnson, R.H.; Chang, C.P.; et al. The Southern China monsoon rainfall experiment (SCMREX). Bull. Am. Meteor. Soc. 2017, 98, 999-1013. [CrossRef]

3. Ryzhkov, A.V.; Giangrande, S.E.; Schuur, T.J. Rainfall estimation with a polarimetric prototype of WSR-88D. J. Appl. Meteorol. 2005, 44, 502-515. [CrossRef]

4. Bringi, V.N.; Chandrasekar, V. Polarimetric Doppler Weather Radar: Principles and Applications; Cambridge University Press: Cambridge, UK, 2001; ISBN 1139429469.

5. You, C.H.; Kang, M.Y.; Hwang, Y.; Yee, J.J.; Jang, M.; Lee, D.I. A statistical approach to radar rainfall estimates using polarimetric variables. Atmos. Res. 2018, 209, 65-75. [CrossRef]

6. Berkowitz, D.S.; Schultz, J.A.; Vasiloff, S.; Elmore, K.L.; Payne, C.D.; Boettcher, J.B. Status of dual pol QPE in the WSR-88D network. In Proceedings of the 93th AMS, 27thConference on Hydrology, Austin, TX, USA, 5-10 January 2013.

7. Chen, G.; Zhao, K.; Zhang, G.; Huang, H.; Liu, S.; Wen, L.; Yang, Z.L.; Yang, Z.W.; Xu, L.; Zhu, W. Improving polarimetric c-band radar rainfall estimation with two-dimensional video disdrometer observations in eastern China. J. Hydrometeorol. 2017, 18, 1375-1391. [CrossRef]

8. Liu, X.; Wan, Q.; Wang, H.; Xiao, H.; Zhang, Y.; Zheng, T.; Feng, L. Raindrop Size Distribution Parameters Retrieved from Guangzhou S-band Polarimetric Radar Observations. J. Meteorol. Res. 2018, 32, 571-583. [CrossRef]

9. Ryzhkov, A.V.; Zrnic, D.S. Discrimination between rain and snow with a polarimetric radar. J. Appl. Meteorol. 1998, 37, 1228-1240. [CrossRef]

10. Brandes, E.A.; Ryzhkov, R.V.; Zrnic, D.S. An evaluation of radar rainfall estimates from specific differential phase. J. Atmos. Ocean Technol. 2001, 18, 363-375. [CrossRef]

11. Bringi, V.N.; Rico-Ramirez, M.A.; Thurai, M. Rainfall estimation with an operational polarimetric C-band radar in the United Kingdom: Comparison with a gauge network and error analysis. J. Hydrometeorol. 2011, 12, 935-954. [CrossRef]

12. Zhang, Y.; Liu, L.; Wen, H.; Wu, C.; Zhang, Y. Evaluation of the Polarimetric-Radar Quantitative Precipitation Estimates of an Extremely Heavy Rainfall Event and Nine Common Rainfall Events in Guangzhou. J. Atmos. 2018, 9, 330. [CrossRef]

13. Zhang, Y.; Liu, L.; He, J.; Wen, H. Application of raindrop size distribution data from a disdrometer network to quantitative precipitation estimation. Torr. Rain Dis. 2016, 35, 173-181.

14. Rosenfeld, D.; Ulbrich, C.W. Cloud microphysical properties, processes, and rainfall estimation opportunities. In Radar and Atmospheric Science: A Collection of Essays in Honor of David Atlas; American Meteorological Society: Boston, MA, USA, 2003; pp. 237-258.

15. Zhang, G.; Sun, J.; Brandes, E.A. Improving parameterization of rain microphysics with disdrometer and radar observations. J. Atmos. Sci. 2006, 63, 1273-1290. [CrossRef]

16. Cao, Q.; Zhang, G.; Brandes, E.A.; Schuur, T.J. Polarimetric radar rain estimation through retrieval of drop size distribution using a Bayesian approach. J. Appl. Meteorol. Climatol. 2010, 49,973-990. [CrossRef]

17. Cifelli, R.; Chandrasekar, V.; Lim, S.; Kennedy, P.C.; Wang, Y.; Rutledge, S.A. A new dual-polarization radar rainfall algorithm: Application in Colorado precipitation events. J. Atmos. Ocean. Technol. 2011, 28, 352-364. [CrossRef]

18. Guo, J.; Wu, Y.; Luo, L.; Xiao, H. Improvement of the Quantitative Precipitation Estimation Algorithm Based on the CINRAD-SA Polarization Radar and Its Application Evaluation. J. Clim. Environ. Res. 2020, 25, 305-319. (In Chinese)

19. Chen, H.; Chandrasekar, V.; Bechini, R. An improved dual-polarization radar rainfall algorithm (DROPS2.0): Application in NASA IFloodS Field Campaign. J. Hydrometeorol. 2017, 18, 917-937. [CrossRef]

20. Ryzhkov, A.; Zrnic, D. Assessment of rainfall measurement that uses specific differential phase. J. Appl. Meteorol. 1996, 35, 2080-2090. [CrossRef]

21. Cifelli, R.; Petersen, W.A.; Carey, L.D.; Rutledge, S.A.; da Silva Dias, M.A. Radar observations of the kinematic, microphysical, and precipitation characteristics of two MCSs in TRMM LBA. J. Geophys. Res. 2002, 107, 2156-22202.

22. Wang, D.; Liu, L.; Wu, F. An optimization rainfall algorithm of s-band dual-polarization radar based on hydrometeor. J. Meteorol. Mon. 2017, 43, 1041-1051.

23. Zhang, Y. Study on the quantitative precipitation estimation algorithm utilized with the operational dual-polarization radar network and automatic stations and its effect analysis. Chin. Acad. Meteorol. Sci. 2019, 15-35.

24. Huang, H.; Zhao, K.; Zhang, G.; Giangrande, S. A hybrid method to estimate specific differential phase and rainfall with linear programming and physics constraints. IEEE Trans. Geosci. Remote Sens. 2016, 54, 1-16. [CrossRef]

25. Giangrande, S.E.; Ryzhkov, A.V. Calibration of dual-polarization radar in the presence of partial beam blockage. J. Atmos. Ocean. Technol. 2005, 22, 1156-1166. [CrossRef]

26. Huang, H. A research on optimization-based rainfall parameter retrieval using polarimetric radar data. Nanjing Univ. 2018, 12-36.

27. Scarchilli, G.; Gorgucci, E.; Chandrasekar, V.; Dobaie, A. Selfconsistency of polarization diversity measurement of rainfall. IEEE Trans. Geosci. Remote Sens. 1996, 34, 22-26. [CrossRef] 
28. Lee, G.W. Sources of errors in rainfall measurements by polarimetric radar: Variability of drop size distributions, observational noise, and variation of relationships between $\mathrm{R}$ and polarimetric parameters. J. Atmos. Ocean. Technol. 2006, 23, 1005-1028. [CrossRef]

29. Guo, Z.; Sun, Z.; Guo, J.; Li, F.; Bu, Z. A Method for Calibrating Zdr by Using Light Rain Echo in Volume Scan Data. In Proceedings of the 2019 International Conference on Meteorology Observations, Chengdu, China, 28-31 December 2020; pp. 1-3.

30. Ma, J.; Chen, M.; Li, S.; Yang, M. Application of linear programming on quality control of differential propagation phase shift data for X-band dual linear polarimetric Doppler weather radar. Acta Meteorol. Sin. 2019, 77, 516-528. (In Chinese)

31. Giangrande, S.E.; McGraw, R.; Lei, L. An application of linear programming to polarimetric radar differential phase processing. J. Atmos. Ocean. Technol. 2013, 30, 1716-1729. [CrossRef]

32. Tokay, A.; Petersen, W.A.; Gatlin, P.; Wingo, M. Comparison of raindrop size distribution measurements by collocated disdrometers. J. Atmos. Ocean. Technol. 2013, 30, 1672-1690. [CrossRef]

33. Wen, L.; Zhao, K.; Zhang, G.F.; Xue, M.; Zhou, B.W.; Liu, S.; Chen, X.C. Statistical characteristics of raindrop size distributions observed in East China during the Asian summer monsoon season using 2-D video disdrometer and Micro Rain Radar data. J. Geophys. Res. Atmos. 2016, 121, 2265-2282. [CrossRef]

34. Feng, L.; Hu, S.; Liu, X.; Xiao, H.; Pan, X.; Xia, F.; Ou, G.; Zhang, C. Precipitation Microphysical Characteristics of Typhoon Mangkhut in Southern China Using 2D Video Disdrometers. Atmosphere 2020, 11, 975. [CrossRef]

35. Wu, H.Y.; Li, Z.H.; Li, W.Y. Characteristics analysis of extremely severe precipitation based on regional automatic weather station in Guangdong. J. Meteorol. Mon. 2020, 46, 801-812.

36. Lee, J.-S.; Grunes, M.R.; de Grandi, G. Polarimetric SAR speckle filtering and its implication for classification. IEEE Trans. Geosci. Remote Sens. 1999, 37, 2363-2373.

37. Wang, H.; Wan, Q.L.; Yin, J.F.; Ding, W.Y. Application of the dual-polarization readr data in numerical modeling studies: Construction of the simulator. Acta Meteorol. Sin. 2016, 74, 229-243.

38. Biondi, D.; Greco, A.; Luciano De Luca, D. Fixed-area vs storm-centered Areal Reduction factors: A Mediterranean case study. J. Hydrol. 2020, 595, 1-51. [CrossRef]

39. Greco, A.; Luca, D.; Avolio, E. Heavy Precipitation Systems in Calabria Region (Southern Italy): High-Resolution Observed Rainfall and Large-Scale Atmospheric Pattern Analysis. Water 2020, 12, 1468. [CrossRef] 